\title{
Molecularly Imprinted Nanofiber Membranes: Localization of Molecular Recognition Sites on the Surface of Nanofiber
}

\author{
Jun Isezaki and Masakazu Yoshikawa*
}

\begin{abstract}
Department of Biomolecular Engineering, Kyoto Institute of Technology, Matsugasaki, Kyoto 606-8585, Japan

Abstract: Two types of molecularly imprinted nanofiber membrane were fabricated from chitosan, adopting Dphenylalanine (D-Phe) or L-phenylalanine (L-Phe) as a print molecule. Molecularly imprinted nanofiber membranes were fabricated by applying a co-axial, two capillary spinneret so that molecular recognition sites could be localized on the surface of formed nanofiber. Though the effect was not so prominent, the amount of molecular recognition site for nanofibers with localized molecular recognition site (core-shell molecularly imprinted nanofiber membranes) was higher than that with delocalized one (usual molecularly imprinted nanofiber membranes). Those membranes showed permselectivity. The enantiomer preferentially incorporated into membrane was selectively transported.
\end{abstract}

Keywords: Chiral separation, core-shell, membrane, electrospray deposition, molecular imprinting, nanofiber membrane, optical resolution, permselectivity.

\section{INTRODUCTION}

Membrane transport phenomena can be explained by a couple of processes, such as incorporation of permeant into membrane and diffusion of it within membrane [1-3]. Diffusivity is mainly determined by dimension and/or shape of permeant [4]. From above, the range of diffusivity is intrinsically limited. Contrary to diffusivity, selectivity of incorporation of permeant into membrane, such as solubility selectivity for a nonporous membrane and partition selectivity for a porous one, is determined by a nature of permeant and combination between permeant and membrane. From this, selectivity of incorporation of permeant into membrane is theoretically ranging from nil to infinity.

From this, introduction of molecular recognition site into membrane is indispensable so that membrane performance can be improved. To this end, alternative molecular imprinting [5-10] and conventional molecular imprinting [7, 9, 11-13] have been applied to membrane preparation to enhance permselectivity. However, a trade-off relationship is often observed in membrane separation. In other words, an enhancement of flux leads to a concurrent reduction in permselectivity and vice versa. Nanofiber fabric has been reported to be a suitable one to enhance a flux without a concurrent reduction in permselectivity [14]. In the case of molecularly imprinted nanofiber membranes, their fluxes were one to two orders of magnitude higher than the corresponding usual molecularly imprinted

\footnotetext{
*Address correspondence to this author at the Department of Biomolecular Engineering, Kyoto Institute of Technology, Matsugasaki, Kyoto 606-8585, Japan; Tel: +81-75-724-7816; Fax: +81-75-724-7800;

E-mail: masahiro@kit.ac.jp
}

membrane without a concurrent reduction in permselectivity [14-19]. Nanofiber membranes from polysulfone showed two to three orders of magnitude higher flux than the usual cast membranes [20]; those nanofiber membranes gave slightly enhanced permselectivity, while the corresponding cast membranes hardly showed permselectivity.

Figure 1 summarizes four types of membrane with molecular recognition site. In a usual cast membrane, as shown in Figure 1a, molecular recognition sites are delocalized within a membrane; that is, molecular recognition sites are dispersed in a membrane. Localization of molecular recognition sites on a surface of a flat membrane might leads to increase in a rate for incorporation of a target molecule into the membrane, which is shown in Figure $\mathbf{1 b}$. The enhancement of amount of molecular recognition site, which theoretically leads to enhancement of concentration of incorporated permeant into membrane. This can be attained by molecularly imprinted nanofiber membrane, which is shown in Figure 1c, since a surface area of nanofiber membrane is a few hundred magnitudes larger than that of usual cast membrane [10]. Even though a total concentration of molecular recognition site for molecularly imprinted nanofiber membrane is high, the molecular recognition sites, located in the central area of the nanofiber, are difficult to be accessed by permeant. From this, molecular recognition sites should be localized on the surface of nanofiber or vicinity of nanofiber surface. As a result, nanofiber membrane, of which molecular recognition sites are localized as shown in Figure 1d, is the most suitable membrane form as a molecular recognition membrane. Such molecularly imprinted nanofiber 
usual cast membranes

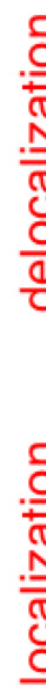

(a)

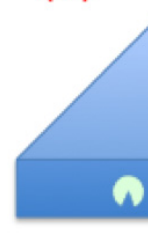

(b)

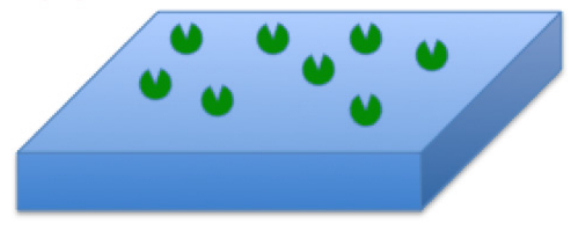

nanofiber membranes

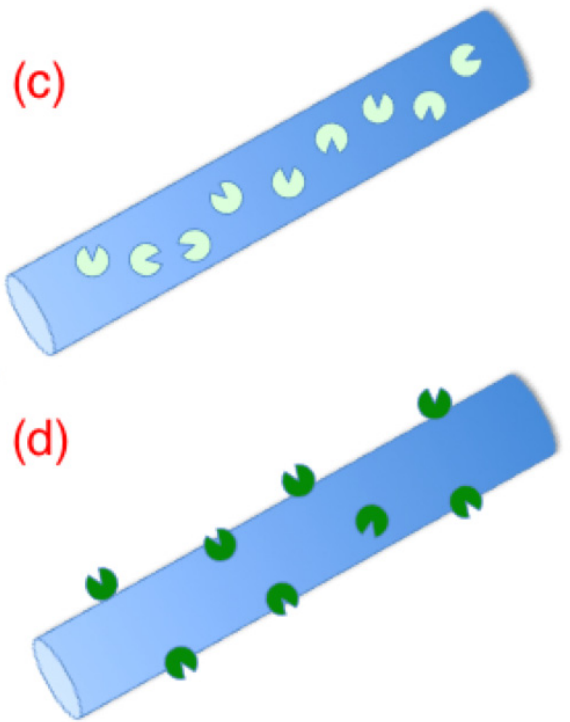

molecular recognition sites found on the surface , molecular recognition sites found inside $\checkmark$, target molecule

Figure 1: Four types of membrane with molecular recognition site.

membranes can be fabricated by applying a co-axial, two capillary spinneret during an electrospray deposition process [21-27].

In the present paper, molecularly imprinted chitosan nanofiber membranes were fabricated by applying a usual single spinneret and a co-axial, two capillary spinneret, and their performance was studied.

\section{ERXPERIMENTAL}

\section{Materials}

Chitosan (CS) from crab shell with degree of acetylation of 0.11 was purchased from Nacalai Tesque, Inc. (Kyoto, Japan) and used as received. 1,1,1,3,3,3-Hexafluoro-2-propanol (HFIP), Dphenylalanine (D-Phe), L-phenylalanine (L-Phe) and sodium azide were also obtained from Nacalai Tesque, Inc. (Kyoto, Japan) and used without further purification. Water purified with an ultrapure water system (Simpli Lab, Millipores S. A., Molsheim, France) was used.

\section{Preparation of Membranes}

The compositions of polymer solution for electrospray deposition are summarized in Table 1. In the present study, a molecular imprinting ratio, the ratio of the mol number of print molecule to that of constitutional repeating unit of chitosan, was fixed to be 2.0. Esprayer ES-2000 (Fuence Co. Ltd., Wako, Japan) was adopted as the electrospray deposition device. Polymer solutions were electrosprayed at $26{ }^{\circ} \mathrm{C}$ using applied voltage of $30.0 \mathrm{kV}$. The inner diameter for the single spinneret was $0.51 \mathrm{~mm}$. As for the co-axial, two capillary spinneret, the inner spinneret for core solution with inner diameter of $0.51 \mathrm{~mm}$ (the outer diameter of $0.81 \mathrm{~mm}$ ) was placed in the outer spinneret with inner diameter of $1.19 \mathrm{~mm}$. The feeding rate for control and usual molecularly imprinred nanofiber membranes was fixed to be $30.0 \mathrm{~mm}^{3} \mathrm{~min}^{-1}$. As for the core-shell nanofiber membranes, both feeding rates for core and shell solution were fixed to be $25.0 \mathrm{~mm}^{3} \mathrm{~min}^{-1}$. A grounded aluminum foil used as a counter electrode was placed $10.0 \mathrm{~cm}$ from the top of the capillary. Nanofiber membranes thus obtained were dried in vacuo at ambient temperature for 2 days.

The print molecule was removed from the resultant nanofiber membranes by a 50 vol. \% aqueous ethanol solution until the print molecule could be hardly detected in the aqueous ethanol one by UV analysis.

The morphology, diameter and thickness of the electrosprayed nanofiber membranes were determined with Hitachi S-3000 scanning electron microscope (SEM). A small section of the nanofiber membrane was 
Table 1: Fabrication of Nanofiber Membranes

\begin{tabular}{|c|c|c|c|c|c|c|c|c|c|}
\hline \multirow[t]{2}{*}{ Membrane } & \multirow[t]{2}{*}{ solution } & \multirow{2}{*}{$\begin{array}{l}\text { chitosan } \\
\mathrm{g}(\mathrm{mol})^{\mathrm{a}}\end{array}$} & \multirow{2}{*}{$\begin{array}{l}\text { D-Phe } \\
\text { g (mol) }\end{array}$} & \multirow{2}{*}{$\begin{array}{l}\text { L-Phe } \\
\text { g (mol) }\end{array}$} & \multirow{2}{*}{$\begin{array}{l}\text { HFIP } \\
\mathrm{cm}^{3}\end{array}$} & \multirow{2}{*}{\multicolumn{2}{|c|}{$(\mathrm{Phe}) /(\mathrm{CS})^{\mathrm{b}}$}} & $\begin{array}{c}\text { Diameter } \\
\text { of fiber }\end{array}$ & $\begin{array}{l}\text { Membrane } \\
\text { thickness }\end{array}$ \\
\hline & & & & & & & & $\mathrm{nm}$ & $\mu \mathrm{m}$ \\
\hline Control & & $\begin{array}{c}0.274 \\
\left(1.65 \times 10^{-3}\right)\end{array}$ & $\begin{array}{l}- \\
(-)\end{array}$ & $\begin{array}{l}- \\
(-)\end{array}$ & 10.0 & \multicolumn{2}{|c|}{-} & $187 \pm 75$ & $295.5 \pm 13.4$ \\
\hline D-Phe-CS & & $\begin{array}{c}0.282 \\
\left(1.70 \times 10^{-3}\right)\end{array}$ & $\begin{array}{c}0.563 \\
\left(1.70 \times 10^{-3}\right)\end{array}$ & $\begin{array}{l}- \\
(-)\end{array}$ & 10.0 & \multicolumn{2}{|c|}{2.0} & $163 \pm 40$ & $213.8 \pm 26.8$ \\
\hline \multirow[t]{2}{*}{ L-Phe-CS } & & $\begin{array}{c}0.278 \\
\left(1.68 \times 10^{-3}\right)\end{array}$ & $\begin{array}{l}- \\
(-)\end{array}$ & $\begin{array}{c}0.555 \\
\left(3.36 \times 10^{-3}\right)\end{array}$ & 10.0 & \multicolumn{2}{|c|}{2.0} & $155 \pm 33$ & $251.7 \pm 56.4$ \\
\hline & & & & & & $(\mathrm{Phe}) /(\mathrm{CS})_{\text {shell }} \mathrm{b}$ & $(\mathrm{Phe}) /(\mathrm{CS})^{\mathrm{b}, \mathrm{c}}$ & & \\
\hline \multirow{2}{*}{$\begin{array}{l}\text { core-shell } \\
\text { D-Phe-CS }\end{array}$} & core & $\begin{array}{c}0.442 \\
\left(2.67 \times 10^{-3}\right)\end{array}$ & $\begin{array}{l}- \\
(-)\end{array}$ & $\begin{array}{l}- \\
(-)\end{array}$ & 15.0 & - & \multirow{2}{*}{2.0} & \multirow{2}{*}{$163 \pm 40$} & \multirow{2}{*}{$392.0 \pm 11.7$} \\
\hline & shell & $\begin{array}{c}0.106 \\
\left(6.22 \times 10^{-4}\right)\end{array}$ & $\begin{array}{c}1.10 \\
\left(6.66 \times 10^{-3}\right)\end{array}$ & $\begin{array}{l}- \\
(-)\end{array}$ & 15.0 & 10.7 & & & \\
\hline \multirow{2}{*}{$\begin{array}{l}\text { core-shell } \\
\text { L-Phe-CS }\end{array}$} & core & $\begin{array}{c}0.441 \\
\left(2.66 \times 10^{-3}\right)\end{array}$ & $\begin{array}{l}- \\
(-)\end{array}$ & $\begin{array}{l}- \\
(-)\end{array}$ & 15.0 & - & \multirow{2}{*}{2.0} & \multirow{2}{*}{$169 \pm 49$} & \multirow{2}{*}{$225.0 \pm 21.5$} \\
\hline & shell & $\begin{array}{c}0.109 \\
\left(6.59 \times 10^{-4}\right)\end{array}$ & $\begin{array}{l}- \\
(-)\end{array}$ & $\begin{array}{c}1.10 \\
\left(6.66 \times 10^{-3}\right)\end{array}$ & 15.0 & 10.1 & & & \\
\hline
\end{tabular}

${ }^{a}$ mole number of constitutional repeating unit of chitosan.

${ }^{\mathrm{b}}$ molecular imprinting ratio.

${ }^{\mathrm{c}}(\mathrm{Phe}) /\left\{(\mathrm{CS})_{\text {shell }}+(\mathrm{CS})_{\text {core }}\right\}$.

placed on the SEM sample holder. The fiber diameter of nanofiber membrane was determined using Image $\mathrm{J}$ software program by measuring at least 30 fibers from each SEM images. As examples, two of SEM images, L-Phe-CS and core-shell L-Phe-CS, which were imprinted by the L-enantiomer of Phe, are shown in Figure 2.

\section{Adsorption Selectivity}

The membrane samples were immersed in a 50 vol.\% aqueous ethanol solution of racemic Phe with a concentration of $2.0 \times 10^{-4} \mathrm{~mol} \mathrm{dm}^{-3}$ and the membrane

(a)

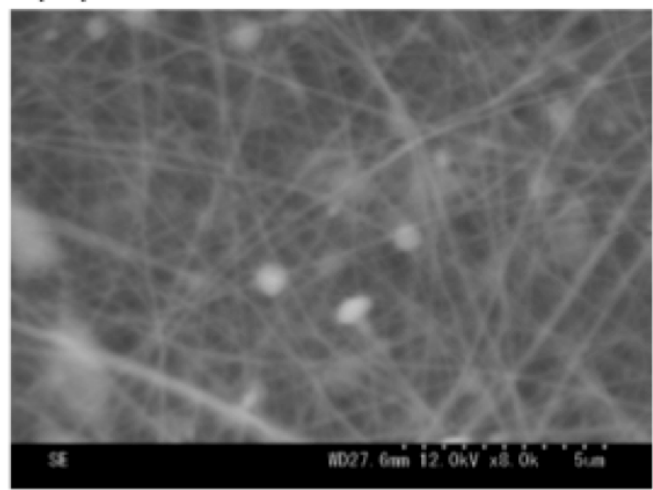

allowed to equilibrate at $40{ }^{\circ} \mathrm{C}$. Sodium azide $(0.02$ wt.\%) was added as fungicide. Aliquots of the initial stage and after equilibrium had been reached were used for quantitative determination by liquid chromatography (LC) [JASCO PU2080, equipped with a UV detector (JASCO UV-2075)] employing a CHIRALPAK MA(+) column [50 mm x $4.6 \mathrm{~mm}$ (i.d.)] (Daicel Co., Osaka, Japan). An aqueous copper sulfate/acetonitrile mixed solution was used as a mobile phase.

The adsorption selectivity $S_{\mathrm{A}(\mathrm{i} j \mathrm{j})}$ is defined as

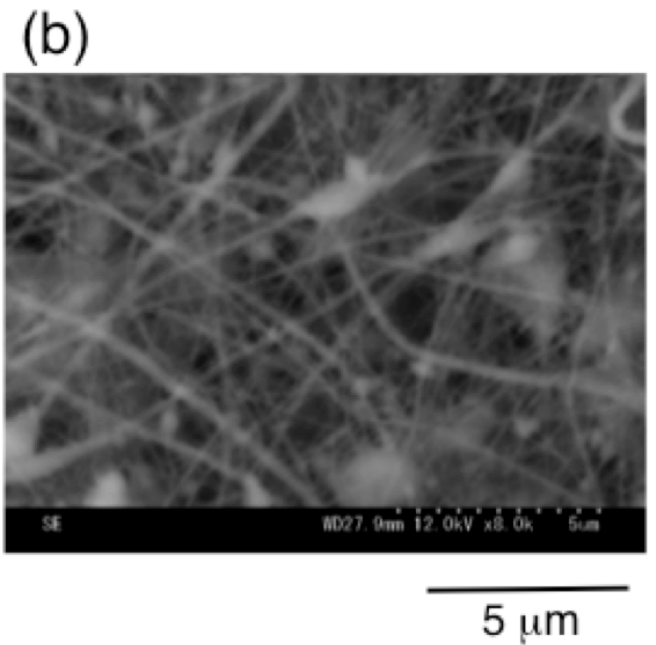

Figure 2: SEM images of surface of L-Phe-CS (a) and core-shell L-Phe-CS (b) molecularly imprinted nanofiber membranes. 
$S_{\mathrm{A}(\mathrm{i} i \mathrm{j})}=((\mathrm{i}-\mathrm{Phe}) /(\mathrm{j}-\mathrm{Phe})) /([\mathrm{i}-\mathrm{Phe}] /[\mathrm{j}-\mathrm{Phe}])$

where (i-Phe) and (j-Phe) denote the amount of Phe adsorbed in the membrane, and [i-Phe] and [j-Phe] are the concentration of Phe in the solution after equilibrium had been reached $(i=D, j=L$ or $i=L, j=D)$, respectively. Hereafter, subscripts of $D$ and $L$ mean the D- and the L-enantiomer of Phe, respectively.

\section{Adsorption Isotherms}

The membrane samples were immersed in various concentrations of pure D- or L-Phe solution and allowed to equilibrate at $40{ }^{\circ} \mathrm{C}$. The quantitative analyses were done as described above. The concentration of Phe in the membrane $[\mathrm{D}-\mathrm{Phe}]_{\mathrm{m}}$ or $[\mathrm{L}-\mathrm{Phe}]_{\mathrm{m}}$ was determined adopting the amount of Phe adsorbed in the membrane and the volume of membrane phase, including that of membrane and that of the solution in the membrane.

\section{Enantioselective Membrane Transport}

Membrane with an area of $3.0 \mathrm{~cm}^{2}$ was tightly secured with Parafilm between two chambers of a permeation cell. The volume of each chamber was 40.0 $\mathrm{cm}^{3}$. A 50 vol.\% aqueous ethanol solution of recemic mixture of Phe was placed in the left-hand side chamber and a 50 vol.\% aqueous ethanol solution in the right-hand side chamber. Each concentration of racemic Phe was $2.0 \times 10^{-4} \mathrm{~mol} \mathrm{dm}^{-3}$. Membrane transport experiments were carried out at $40{ }^{\circ} \mathrm{C}$ with stirring. An aliquot was drawn from the permeate side at each sampling time. The amounts of D- and L-Phe transported through the membrane were determined by LC as described above.

The flux, $J\left(\mathrm{~mol} \mathrm{~cm} \mathrm{~cm} \mathrm{~h}^{-1}\right)$, is defined as

$J=\left\{\left(\mathrm{d}[\mathrm{i}-\mathrm{Phe}]_{\mathrm{R}} / \mathrm{d} t\right)\left(V_{\mathrm{R}} / 1000\right) \delta\right\} / A$ where $[i-P h e]_{R}\left(\mathrm{~mol} \mathrm{dm}^{-3}\right)$ is the concentration of $\mathrm{i}$ enantiomer in the right-hand side chamber (permeate side), $t$ is the time $(\mathrm{h}), V_{\mathrm{R}}\left(\mathrm{cm}^{3}\right)$ denotes the volume of the right-hand side chamber, $\delta(\mathrm{cm})$ is membrane thickness, and $A\left(\mathrm{~cm}^{2}\right)$ represents membrane area, respectively.

The permselectivity toward i-enantiomer, $\alpha_{i j}$, is defined as the flux ratio, $J_{\mathrm{i}} / J_{\mathrm{j}}$, divided by the concentration ratio [i-Phe] / [j-Phe]:

$\alpha_{\mathrm{ijj}}=\left(J_{\mathrm{i}} / J_{\mathrm{j}}\right) /([\mathrm{i}-\mathrm{Phe}] /[\mathrm{j}-\mathrm{Phe}])$

\section{RESULTS AND DUSCUSSION}

\section{Adsorption of Racemic Phe}

Adsorption phenomena for those five types of nanofiber membrane, such as control, usual nanofiber and core-shell nanofiber membranes, are summarized in Table 2. The control membrane slightly showed adsorption selectivity toward L-Phe. This might be due to the fact that chitosan is chiral.

Molecularly imprinted nanofiber membranes, both usual and core-shell nanofiber membranes, showed adsorotion selectivity. Applying an alternative molecular imprinting during an electrospray deposition process led to enhancement of adsorption selectivity. Though chitosan is chiral, both print molecules, such as D-Phe and L-Phe, equally worked well as print molecules. That is, the D-enantiomer recognition sites were constructed in the nanofiber membranes imprinted by adopting D-Phe as a print molecule and vice versa. The adsorption selectivity for each membrane gave a quite similar value. However, against expectation mentioned in Introduction, core-shell molecularly imprinted nanofiber membranes did not show higher adsorption selectivity. A strict optimization of nanofiber fabrication, such as voltage, distance between collector (counter

Table 2: Adsorption Selectivity of Various Chitosan Membranes

\begin{tabular}{|c|c|c|c|c|c|c|}
\hline \multirow{2}{*}{ Membrane } & \multicolumn{2}{|c|}{ D-Phe } & \multicolumn{2}{|c|}{ L-Phe } & \multirow{2}{*}{$S_{A(D / L)}^{b}$} & \multirow{2}{*}{$S_{A(L / D)}{ }^{c}$} \\
\hline & (D-Phe)/g-mem. & (D-Phe)/CRU & (L-Phe)/g-mem. & (L-Phe)/CRU ${ }^{\mathrm{a}}$ & & \\
\hline control & $1.19 \times 10^{-6}$ & $1.98 \times 10^{-4}$ & $1.22 \times 10^{-6}$ & $2.03 \times 10^{-4}$ & 0.98 & 1.03 \\
\hline D-Phe-CS & $1.56 \times 10^{-6}$ & $2.58 \times 10^{-4}$ & $1.20 \times 10^{-6}$ & $1.99 \times 10^{-4}$ & 1.30 & 0.77 \\
\hline L-Phe-CS & $1.30 \times 10^{-6}$ & $2.15 \times 10^{-4}$ & $1.70 \times 10^{-6}$ & $2.82 \times 10^{-4}$ & 0.76 & 1.31 \\
\hline core-shell D-Phe-CS & $2.79 \times 10^{-6}$ & $4.62 \times 10^{-4}$ & $2.27 \times 10^{-6}$ & $3.76 \times 10^{-4}$ & 1.23 & 0.81 \\
\hline core-shell L-Phe-CS & $3.43 \times 10^{-6}$ & $5.68 \times 10^{-4}$ & $4.18 \times 10^{-6}$ & $6.91 \times 10^{-4}$ & 0.82 & 1.22 \\
\hline
\end{tabular}

${ }^{a}$ mole number of constitutional repeating unit (CRU) of chitosan.

${ }^{\mathrm{b}} \mathrm{S}_{\mathrm{A}(\mathrm{D} / \mathrm{L})}=((\mathrm{D}-\mathrm{Phe}) /(\mathrm{L}-\mathrm{Phe})) /([\mathrm{D}-\mathrm{Phe}] /[\mathrm{L}-\mathrm{Phe}])$

${ }^{\mathrm{C}} \mathrm{S}_{\mathrm{A}(\mathrm{L} / \mathrm{D})}=((\mathrm{L}-\mathrm{Phe}) /(\mathrm{D}-\mathrm{Phe})) /([\mathrm{L}-\mathrm{Phe}] /[\mathrm{D}-\mathrm{Phe}])$. 
(a)

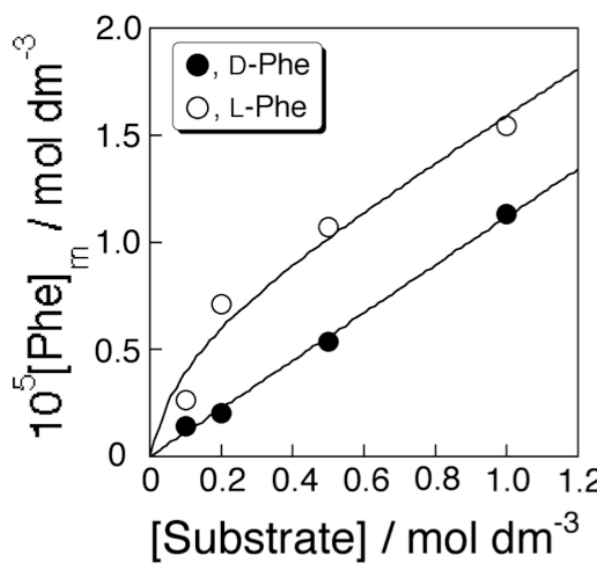

(b)

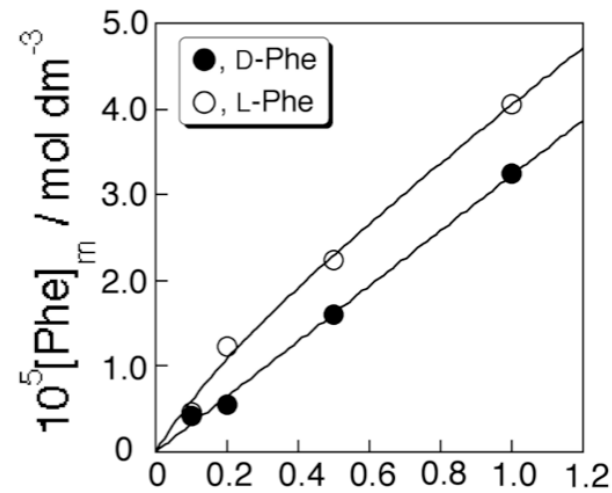

[Substrate] $/ \mathrm{mol} \mathrm{dm}^{-3}$

Figure 3: Adsorption isotherms of D-Phe and L-Phe for L-Phe-CS membrane (a) and core-shell L-Phe-CS membrane (b).

electrode) and tip, diameter of capillary, feeding rate, temperature, humidity, type of atmosphere, pressure, concentration of feed solution, molecular weight of candidate material and so forth, is required to attain higher adsorption selectivity of core-shell molecularly imprinted nanofiber membrane.

Adsorption isotherms of two types of nanofiber membranes imprinted by the L-Phe are given in Figure 3. Adsorption isotherms of L-Phe for both membranes show those of dual adsorption, which consists of specific adsorption on the L-Phe recognition site and non-specific adsorption, while D-Phe show non-specific adsorption. The adsorption isotherm of L-Phe can be represented by the following equation [28]:

$$
\begin{aligned}
{[\mathrm{L}-\mathrm{Phe}]_{\mathrm{m}}=} & k_{\mathrm{A}}[\mathrm{L}-\mathrm{Phe}] \\
& +K_{\mathrm{S}}[\text { Site }]_{0}[\mathrm{~L}-\mathrm{Phe}] /\left(1+K_{\mathrm{S}}[\mathrm{L}-\mathrm{Phe}]\right)
\end{aligned}
$$

where $[\mathrm{L}-\mathrm{Phe}]_{\mathrm{m}}$ means the concentration of L-Phe adsorbed in the membrane, $k_{\mathrm{A}}$ denotes non-specific adsorption constant, $K_{\mathrm{S}}$ is affinity constant between LPhe and L-Phe molecular recognition site, [Site $]_{0}$ denotes concentration of molecular recognition site in the membrane. Though molecular recognition sites in those two types of membrane were constructed adopting L-Phe as a print molecule, the formed molecular recognition sites might specifically recognize not only L-Phe but also other amino acids with Lconfiguration like molecularly imprinted oligopeptide derivatives [29].

As can be seen, D-Phe was non-specifically incorporated into those two types of L-Phe molecularly imprinted nanofiber membrane. The adsorption isotherm of D-Phe can be represented by the following equation:
$[\mathrm{D}-\mathrm{Phe}]_{\mathrm{m}}=k_{\mathrm{A}}[\mathrm{D}-\mathrm{Phe}]$

The adsorption constant of non-specific adsorption for D-Phe should be same as that for L-Phe. Since, non-specific adsorption of each enantiomer of Phe, which was an adsorption without any specific interaction, was occurred without the interference of non-specific adsorption of antipode.

The D-enantiomer molecularly imprinted nanofiber membrane is expected to show opposite adsorption isotherms [28]. That is, the adsorption isotherm of DPhe will show a dual adsorption one, while L-Phe will be non-specifically adsorbed.

The parameters in those adsorption equations (eqs. (4) and (5)), which were determined to fit each adsorption isotherm in Figure 3 best, are summarized in Table 3. As expected, the concentration of molecular recognition site for core-shell nanofiber membrane was higher than that for usual nanofiber membrane, though the enhancement of concentration was not prominent against expectation. The adsorption constant for coreshell nanofiber membrane was increased over 3 times than that for usual nanofiber membrane. This can be speculated as follows: print molecules, which did not work well, played as just porogens to increase surface area of nanofiber membranes. At the moment, there is no suitable method to investigate the surface of those nanofiber membranes precisely. However, from the affinity constant between L-Phe and molecular recognition site, as envisaged from the authors' previous study [30], that for core-shell nanofiber membrane was lower than that of usual one. The increase in amount of print molecule leads to decrease in number of functional moieties in the candidate 
Table 3: Parameters for Adsorption Isotherms

\begin{tabular}{|c|c|c|c|}
\hline Membrane & $\boldsymbol{k}_{\mathrm{A}}$ & $\boldsymbol{K}_{\mathbf{S}} / \mathbf{m o l}^{-1} \mathbf{d m}^{\mathbf{3}}$ & {$[\text { Site }]_{0} / \mathbf{m o l ~ d m}^{-3}$} \\
\hline \hline L-Phe-CS & $1.05 \times 10^{-2}$ & $5.79 \times 10^{3}$ & $5.24 \times 10^{-6}$ \\
\hline core-shell L-Phe-CS & $3.37 \times 10^{-2}$ & $3.11 \times 10^{3}$ & $9.14 \times 10^{-6}$ \\
\hline
\end{tabular}

polymer, which interacted with the print molecule; as a result, the affinity constant was decreased.

A print molecule, which interacts with a candidate polymer via non-covalent interaction [31] to memorize molecular memory, is solely sprayed accompanying no polymer molecule. This led to the present results, which were against expectation. Adoption of a covalent molecular imprinting technique [32] will lead to fruitful results, though this requires experience of organic synthesis and great effort and time.

\section{Enantioselective Transport of Racemic Phe}

As examples, time-transport curves of racemic Phe through L-Phe-CS and core-shell L-Phe-CS

(a)

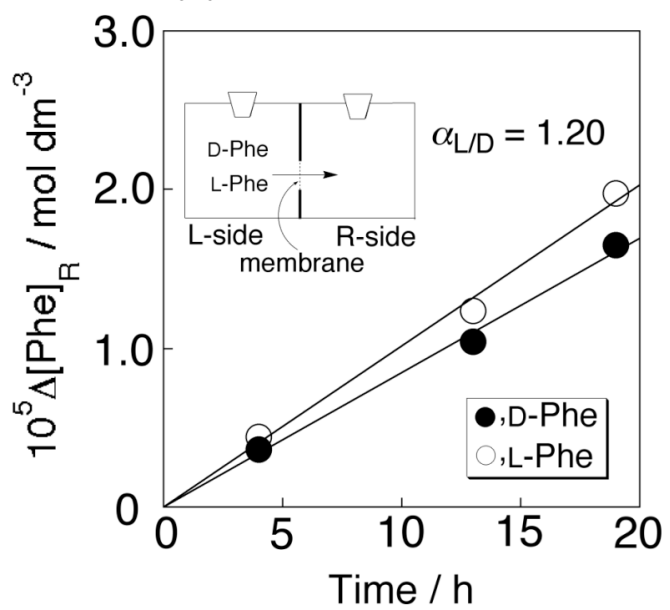

membranes are shown in Figure 4. The results for various chitosan nanofiber membranes are summarized in Table 4. Optical resolution membranes often showed permselectivity, which was opposite to adsorption selectivity due to a relatively strong interaction between preferentially incorporated enantiomer and membrane [28,33-40]. Against this, permselectivities for those membranes reflected the corresponding adsorption selectivities; in other words, the membrane preferentially incorporated D-Phe transported D-Phe over L-Phe and vice versa.

In the present study, as described in Introduction, membrane transport phenomena can be explained by incorporation of permeant into a membrane and diffusion of it within a membrane. From this (b)

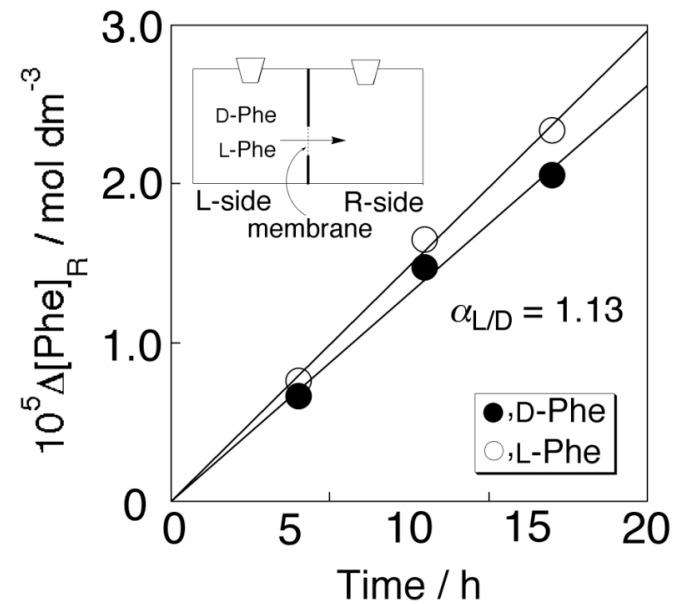

Figure 4: Time-transport curves of racemic Phe through L-Phe-CS membrane (a) and core-shell L-Phe-CS membrane (b).

Table 4: Chiral Separation of Racemic Phe through Various Chitosan Membranes

\begin{tabular}{|c|c|c|c|c|}
\hline \multirow{2}{*}{ Membrane } & $10^{10} J_{D}$ & $10^{10} \mathrm{~J}_{\mathrm{L}}$ & \multirow{2}{*}{$\alpha_{\mathrm{D} / \mathrm{L}}^{\mathrm{a}}$} & \multirow[t]{2}{*}{$\alpha_{\mathrm{LID}}^{\mathrm{b}}$} \\
\hline & $\mathrm{mol} \mathrm{cm} \mathrm{cm} \mathrm{ch}^{-1}$ & $\mathrm{~mol} \mathrm{~cm} \mathrm{~cm} \mathrm{ch}^{-2}$ & & \\
\hline control & 12.4 & 12.8 & 0.97 & 1.03 \\
\hline D-Phe-CS & 7.92 & 6.38 & 1.24 & 0.81 \\
\hline L-Phe-CS & 2.85 & 3.42 & 0.83 & 1.20 \\
\hline core-shell D-Phe-CS & 5.41 & 4.80 & 1.13 & 0.89 \\
\hline core-shell L-Phe-CS & 5.24 & 5.93 & 0.88 & 1.13 \\
\hline
\end{tabular}

${ }^{\mathrm{a}} \alpha_{\mathrm{D} / \mathrm{L}}=\left(J_{\mathrm{D}} / J_{\mathrm{L}}\right) /([\mathrm{D}-\mathrm{Phe}] /[\mathrm{L}-\mathrm{Phe}])$.

${ }^{\mathrm{b}} \alpha_{\mathrm{L} / \mathrm{D}}=\left(J_{\mathrm{L}} / J_{\mathrm{D}}\right) /([\mathrm{L}-\mathrm{Phe}] /[\mathrm{D}-\mathrm{Phe}])$ 
Table 5: Result of Membrane Transports*

\begin{tabular}{|c|c|c|c|c|c|c|}
\hline Membrane & $\alpha_{\mathrm{D} / \mathrm{L}}$ & $\alpha_{\mathrm{L} / \mathrm{D}}$ & $\boldsymbol{S}_{\mathrm{A}(\mathrm{D} / \mathrm{L})}$ & $\boldsymbol{S}_{\mathrm{A}(\mathrm{L} / \mathrm{D})}$ & $\boldsymbol{S}_{\mathrm{D}(\mathrm{D} / \mathrm{L})}$ & $\boldsymbol{S}_{\mathrm{D}(\mathrm{L} / \mathrm{D})}$ \\
\hline \hline control & 0.97 & 1.03 & 0.98 & 1.03 & 1.00 & 1.00 \\
\hline D-Phe-CS & 1.24 & 0.81 & 1.30 & 0.77 & 0.95 & 1.05 \\
\hline L-Phe-CS & 0.83 & 1.20 & 0.76 & 1.31 & 0.92 \\
\hline core-shell D-Phe-CS & 1.13 & 0.89 & 1.23 & 0.81 & 0.92 & 1.09 \\
\hline core-shell L-Phe-CS & 0.88 & 1.13 & 0.82 & 1.22 & 1.07 & 0.93 \\
\hline
\end{tabular}

${ }^{*} S_{\mathrm{D}(\mathrm{i} / \mathrm{j})}=\alpha_{\mathrm{i} / \mathrm{j}} / \mathrm{S}_{\mathrm{A}(\mathrm{i} / \mathrm{j})}$.

permselectivity observed consists of adsorption selectivity $\left(S_{\mathrm{A}(\mathrm{i} / \mathrm{j})}=S_{\mathrm{i}} / S_{\mathrm{j}}\right.$; ratio of adsorption coefficient) and diffusivity selectivity $\left(S_{\mathrm{D}(\mathrm{i} j \mathrm{j})}=D_{\mathrm{i}} / D_{\mathrm{j}}\right.$; ratio of diffusion coefficient). Diffusivity selectivity for each membrane was calculated by the following equation:

$S_{D(i j)}=\alpha_{i j j} / S_{A(i j)}$

The diffusivity selectivities for the present membranes are summarized in Table $\mathbf{5}$ together with permselectivities and adsorption selectivities. In the case of control membrane, two types of enantiomer are transported following a simple diffusion, since they were non-specifically incorporated into the membrane. From this, diffusivity for the enantiomer and that for the antipode should give same diffusion coefficients, since they have exactly same dimension and shape [4]. As a result, the diffusivity selectivity for the control membrane was determined to be unity.

Contrary to the diffusivity selectivity for the control nanofiber membranes, the diffusivity selectivity for the molecularly imprinted nanofiber membranes showed opposite adsorption selectivity though enantioemers, such as D-Phe and L-Phe, have same molecular dimension and shape. This might be due to a relatively strong interaction between membrane and the enantiomer preferentially incorporated into a membrane. Such an interaction retarded the diffusion of enantiomer within a membrane, as a result, the antipode was transferred from feed side to the permeate side faster than the enantiomer selectively incorporated.

Against expectation, a drastic enhancement of membrane performance, such as that of concentration of molecular recognition site and permselectivity, was not attained, even though core-shell molecularly imprinted nanofiber membranes were tried to obtain. This might be due to a type of molecular imprinting method adopted in the present study. In the present study the interaction between print molecule and candidate polymer to form molecularly imprinted nanofiber membrane was non-covalent interaction. When non-covalent molecular imprinting [31] was adopted as a molecular imprinting method, most of print molecule was sprayed solely accompanying no polymer molecule [16]. As a result, the amount of print molecule worked well was drastically decreased. To this end, covalent molecular imprinting [32] should be applied to fabrication of core-shell molecularly imprinted nanofiber membranes, even though the operation might be more complicated than applying non-covalent molecular imprinting.

\section{CONCLUSIONS}

Two types of molecularly imprinted nanofiber membrane were fabricated from chitosan, adopting DPhe or L-Phe as a print molecule. Molecularly imprinted nanofiber membranes were fabricated by applying a co-axial, two capillary spinneret so that molecular recognition sites could be localized on the surface of formed nanofiber. Though the effect was not so prominent, the amount of molecular recognition site for nanofibers with localized molecular recognition site (core-shell molecularly imprinted nanofiber membranes) was higher than that with delocalized one (usual molecularly imprinted nanofiber membranes). Those membranes showed permselectivity. The enantiomer preferentially incorporated into membrane was selectively transported.

\section{REFERENCES}

[1] Ho WSW, Sirkar KK, Eds. Membrane Handbook. New York: Chapman \& Hall; 1992. http://dx.doi.org/10.1007/978-1-4615-3548-5

[2] Mulder M, Basic principles of membrane technology. 2nd ed. Dordrecht: Kluwer Academic Publishers; 1996.

[3] Baker RW, Membrane technology ad applications. 2nd ed West Sussex: Wiley; 2004.

[4] Bitter JGA, Transport mechanism in membrane separation processes. New York: Plenum Press; 1991.

[5] Michaels AS, Baddour RF, Bixler HJ, Choo CY. Ind Eng Chem Process Des Dev 1962; 1:14-25. http://dx.doi.org/10.1021/i260001a003 
[6] Yoshikawa M, Molecularly imprinted polymeric membranes for optical resolution. In: Bartsch RA, Maeda M, editors. Molecular and ionic recognition with imprinted polymers. ACS Symposium Series 703. Washington DC: ACS 1998; p. 170187.

[7] Piletsky SA, Panasyuk TL, Piletskaya EV, Nicholls IA, Ulbricht M, J Membr Sci 1999; 157: 263-78. http://dx.doi.org/10.1016/S0376-7388(99)00007-1

[8] Yoshikawa M, Bioseparation 2002; 10: 277-86. http://dx.doi.org/10.1023/A:1021537602663

[9] Ulbricht M, J Chromatogr B 2004; 804: 113-25. http://dx.doi.org/10.1016/j.jchromb.2004.02.007

[10] Yoshikawa M, Higuchi A. Enantioselective membrane. In: Hoek EMV, Tarabara VV, editors. Encyclopedia of membrane science and technology. New York: Wiley; 2013. http://dx.doi.org/10.1002/9781118522318.emst131

[11] Wulff G. Angew Chem Int Ed Engl 1995; 34: 1812-32. http://dx.doi.org/10.1002/anie.199518121

[12] Haupt K, Mosbach K. Chem Rev 2000; 100: 2495-504. http://dx.doi.org/10.1021/cr990099w

[13] Maier NM, Lindner W. Anal Bioanal Chem 2007; 389: 37797.

http://dx.doi.org/10.1007/s00216-007-1427-4

[14] Yoshikawa M, Tanioka A, Matsumoto H. Curr. Opinion Chem Eng 2011; 1: 18-26. http://dx.doi.org/10.1016/j.coche.2011.07.003

[15] Yoshikawa M, Nakai K, Matsumoto H, Tanioka A, Guiver MD, Robertson GP. Macromol Raip Commun 2007; 28: 2100-5. http://dx.doi.org/10.1002/marc.200700359

[16] Sueyoshi Y, Fukushima C, Yoshikawa M. J Membr Sci 2010; 357: $90-7$ http://dx.doi.org/10.1016/j.memsci.2010.04.005

[17] Sueyoshi $Y$, Utsunomiya A, Yoshikawa M, Robertson GP, Guiver GP. J Membr Sci 2012: 401-402: 89-96. http://dx.doi.org/10.1016/j.memsci.2012.01.033

[18] Kawasaki T, Yoshikawa M. Desal Water Treat 2013; 51: 5080-8.

http://dx.doi.org/10.1080/19443994.2013.768832

[19] Shiomi K, Yoshikawa M. Sep Purif Technol 2013; 118: 300-4. http://dx.doi.org/10.1016/j.seppur.2013.07.004

[20] Mizushima H, Yoshikawa M, Li N, Robertson GP, Guiver MD. Eur Polym J 2012; 48: 1717-25. http://dx.doi.org/10.1016/j.eurpolymj.2012.07.003

[21] Sun Z, Zussman E, Yarin AL, Wendorff JH, Greiner A. Adv Mater 2003; 15: 1929-32. http://dx.doi.org/10.1002/adma.200305136

[22] Li D, Xia Y. Nano Lett 2004; 4: 933-8. http://dx.doi.org/10.1021/nl049590f
[23] Li D, McCann JT, Xia Y Small 2005; 1: 83-6. http://dx.doi.org/10.1002/smll.200400056

[24] Ramakrishna S, Fujihara K, Teo W-E, KLim T-C, Ma Z. An introduction to electrospinning and nanofibers. Singapore: World Scientific; 2005

[25] McCann JT, Li D, Xia Y. J Mater Chem 2005; 15: 735-8. http://dx.doi.org/10.1039/b415094e

[26] Greiner A, Wendorff JH. Angew Chem Int Ed 2007; 46: 5670703. http://dx.doi.org/10.1002/anie.200604646

[27] Matsumoto H, Tanioka A. Membranes 2011; 1: 249-64. http://dx.doi.org/10.3390/membranes1030249

[28] Yoshikawa M, Izumi J. Macromol Biosci 2003; 3: 487-98. http://dx.doi.org/10.1002/mabi.200350016

[29] Yoshikawa M, Izumi J, Kitao T. Polym J 1997; 29: 205-10. http://dx.doi.org/10.1295/polymj.29.205

[30] Taniwaki K, Hyakutake A, Aoki T, Yoshikawa M, Guiver MD, Robertson GP. Anal Chim Acta 2003; 489: 191-8. http://dx.doi.org/10.1016/S0003-2670(03)00760-8

[31] Arshady R, Mosbach K. Makromol Chem 1981; 182: 687-92. http://dx.doi.org/10.1002/macp.1981.021820240

[32] Wulff G, Sarhan A. Angew Chem Int Ed 1972; 11: 341 [Angew Chem 1972; 84:364]. 10.1002/macp. 1981.021820240 [10.1002/ange.19720840838]

[33] Kakuchi T, Takaoka T, Yokota K. Polym J 1990; 22: 199-05. http://dx.doi.org/10.1295/polymj.22.199

[34] Masawaki T, Sasai M, Tone S. J Chem Eng Jpn 1992; 25 : 33-9. http://dx.doi.org/10.1252/jcej.25.33

[35] Aolki T, Tomizawa S, Oikawa E. J Membr Sci 1995; 99: 11725 http://dx.doi.org/10.1016/0376-7388(94)00199-9

[36] Tone S, Masawaki T, Eguchi K. J Membr Sci 1996; 118: 31 40. http://dx.doi.org/10.1016/0376-7388(96)00071-3

[37] Yoshikawa M, Izumi J, Kitao T. React Funct Polym 1999; 42: 93-102. http://dx.doi.org/10.1016/S1381-5148(98)00063-7

[38] Yoshikawa M, Fujisawa T, Kitao T. Macromol Chem Phys 1999; 200: 1458-65.

http://dx.doi.org/10.1002/(SICI)15213935(19990601)200:6<1458::AID-MACP 1458>3.0.CO;2-D

[39] Wang H-D, Chu L-Y, Song H, Yang J-P, Xie R, Yang N. J Membr Sci 2007; 297: 262-70. http://dx.doi.org/10.1016/j.memsci.2007.03.055

[40] Hazarika S. J Membr Sci 2008; 310: 174-83. http://dx.doi.org/10.1016/..memsci.2007.10.055

\section{DOI: http://dx.doi.org/10.6000/1929-6037.2014.03.03.2}

(C) 2014 Isezaki and Yoshikawa; Licensee Lifescience Global.

This is an open access article licensed under the terms of the Creative Commons Attribution Non-Commercial License (http://creativecommons.org/licenses/by-nc/3.0/) which permits unrestricted, non-commercial use, distribution and reproduction in any medium, provided the work is properly cited. 